\title{
Carneiro Leão: considerações acerca da sociologia educacional
}

Carneiro Leão: considerations about the prospect of educational sociology

\author{
Rosilene de Lima* \\ Universidade Estadual de Maringá \\ Maria Cristina Gomes Machado** \\ Universidade Estadual de Maringá
}

Resumo Este artigo apresenta algumas considerações acerca da Sociologia Educacional na perspectiva de Antônio Carneiro Leão (1887-1966). Considera-se pertinente, num primeiro momento, discutir alguns dados biográficos deste importante intelectual brasileiro, bem como clarificar algumas concepções de Carneiro Leão no que tange à Sociologia Educacional, analisando o pensamento do autor sobre a mesma. Para tanto, tomaram-se como principais fontes de pesquisa os livros Fundamentos de Sociologia, cuja primeira edição data de 1940, e Panorama Sociológico do Brasil, publicado em 1958. Parte-se do pressuposto de que ambas as publicações dão referências e subsídios para que se possa compreender as concepções de Carneiro Leão acerca da Sociologia Educacional.

PALAVRAS-ChAVE: Carneiro Leão, Sociologia Educacional, Educação.

Abstract This article presents a description of some considerations about the prospect of Educational Sociology of Antônio Carneiro Leão (18871966). It is considered and appropriated, at first reviewing some of this important bibliographic Brazilian intellectual, as well as we seek to explain some Carneiro Leão conceptions about the Educational Sociology, analyzing the author's though about it. So, we worked as research sources the books: Foundations of Sociology (1963), which the first edition dates 1940, and "Sociology Vision of Brazil", published in 1958 We believe that both publications give us referrals and subsidies for we can understand the Carneiro Leão conceptions about the Educational Sociology.

KEYWORDS: Carneiro Leão, Educational Sociology, Education. 


\section{Introdução}

Este artigo apresenta considerações acerca da Sociologia Educacional na perspectiva de Antônio Carneiro Leão (1887-1966). Esta temática consubstancia-se em importante objeto de investigação de uma pesquisa desenvolvida pelo Programa de Pós-graduação em Educação da Universidade Estadual de Maringá, no âmbito da história e historiografia da educação, tendo em vista que a Sociologia Educacional tem obtido cada vez mais espaço na ambiência acadêmica, na pesquisa e no ensino, tornando-se presente nos diversos cursos de licenciatura das mais conceituadas universidades do país.

Com o intuito de se obter uma melhor compreensão dos resultados que a investigação proporcionou, consideramos pertinente, primeiramente, analisar alguns aspectos biográficos deste importante intelectual pernambucano, demonstrando, dessa forma, a sua relevância, bem como a sua atuação política e educacional no cenário brasileiro. De posse de tais conhecimentos, objetivamos trazer ao leitor dados levantados pela pesquisa, a fim de clarificar algumas concepções de Carneiro Leão no que tange à Sociologia Educacional, analisando o pensamento do autor sobre a mesma.

Para tanto, tomamos como principais fontes de pesquisa os livros Fundamentos de Sociologia, cuja primeira edição data 1940, por constituir-se, segundo Leão (1963), em um conjunto de lições com o objetivo de familiarizar os estudiosos da Sociologia com as técnicas sociológicas que considerava adequadas na Universidade do Distrito Federal, e Panorama Sociológico do Brasil, publicado em 1958, estudo que apresenta alguns aspectos dos fatos sociológicos referentes à civilização e à cultura desenvolvidas no Brasil (LEÃO, 1958). Acreditamos que ambas as publicações nos dão referências e subsídios para que possamos compreender as concepções de Carneiro Leão acerca da Sociologia Educacional.

Optou-se por Antônio Carneiro Leão, intelectual de expressividade no que se refere à temática proposta, por entendermos que o autor, além de estar extremamente envolvido na política e economia do Estado brasileiro, conforme apresenta Silva (2006), fundamentou seu trabalho na modernização do sistema educacional e no embasamento científico de todo o ensino e atividades escolares.

Consideramos, portanto, relevante uma análise das concepções de Antônio Carneiro Leão acerca da Sociologia em seus aspectos educacionais. O trabalho de investigação proposto está em sintonia não só com as demandas que permeiam esta esfera de conhecimento na atualidade, mas, fundamentalmente, porque é sabido que, em torno da disciplina de Sociologia da Educação, concentra-se um grande interesse, que pode ser observado na disposição das disciplinas na estrutura curricular dos cursos atuais de formação de professores.

\section{Carneiro Leão: dados biográficos}

Antônio de Arruda Carneiro Leão, filho de Antônio Carlos Carneiro Leão e Elvira Cavalcanti de Arruda Câmara Carneiro Leão, nasceu em 02 de julho de 
1887, na cidade de Recife, capital de Pernambuco. Neste Estado, realizou seus estudos primário e secundário e tornou-se bacharel em Ciências Jurídicas e Sociais pela Faculdade de Direito do Recife, em 15 de dezembro de 1911 (NISKIER, 2001). Dedicouse ao magistério universitário, ministrando a disciplina de Filosofia na Faculdade do Recife.

Mudou-se para o Rio de Janeiro em 1914 e continuou trabalhando na área educacional, tendo sido nomeado Diretor Geral da Instrução Pública no Rio de Janeiro, em 1922. Nessa oportunidade, Leão fundou dezenas de escolas no referido Estado e deixou o cargo no ano de 1926. De volta a Recife, empreendeu a Reforma Educacional de Pernambuco em 1928, na qual inovou os métodos pedagógicos, colocando a educação de Pernambuco entre as mais modernas do país.

Foi Secretário de Estado do Interior, Justiça e Educação daquele Estado no período que compreende 1929 a 1930. Ao ser nomeado Diretor do Instituto de Pesquisas Educacionais em 1934, criou e dirigiu o Centro Brasileiro de Pesquisas Pedagógicas da Universidade do Brasil.

Leão esteve extremamente engajado nas questões educacionais. Foi professor universitário em várias instituições nacionais. Visitou e realizou conferências em Universidades de países como Estados Unidos, França, Uruguai e Argentina. Além do magistério, dedicou-se, ainda, ao jornalismo, colaborando com jornais do Recife, Rio de Janeiro e São Paulo, e fundou e dirigiu O Economista (1920-1927).

O educador, advogado e jornalista, entre outras atividades que exerceu, nutriu grande afeto por Madeleine Sathie Augustine Manuelle, professora catedrática de Língua e Literatura Francesa da Faculdade Nacional de Filosofia, com a qual se casou.

No período entre 1945 e 1957, Leão foi diretor (decano) da Faculdade Nacional de Filosofia da Universidade do Brasil, tendo pertencido a diversas instituições. Destacamos aqui sua estadia como membro do Instituto de França, onde substituiu o célebre educador John Dewey.

O currículo do autor é expressivo e imensa é a lista dos títulos honoríficos que recebeu: foi professor emérito da Faculdade de Filosofia da Universidade do Brasil, Doutor Honoris Causa em Filosofia e Letras pela Universidade de Paris, Doutor Honoris Causa pela Universidade Autônoma do México, membro Honoris Causa das Universidades argentinas de Buenos Aires, La Plata, Cordoba, Tucuman, Cuyo, Litoral e do Instituto Argentino de Sociologia e da Sociedade Boliviana de Sociologia. Presidente Honoris Causa da Conferência de Educação em Quito em 1951, vice-presidente de honra do $4^{\circ}$ Congresso Latino-Americano de Sociologia, reunido no Chile, em julho de 1957. Também foi oficial da Legião de Honra da França e da Ordem do Leão Branco da Tchecoslováquia, membro do Instituto Histórico e Geográfico Brasileiro, do Instituto de França, da Real Academia Espanhola, da Academia das Ciências de Lisboa e de inúmeras outras associações acadêmicas internacionais.

Pelo conjunto de sua obra, pode ser observada a relevância de Carneiro Leão. Destacaremos apenas as publicações em português, listadas no livro de sua au- 
toria Panorama Sociológico do Brasil, de 1958, entretanto, possui livros publicados em inglês, francês e espanhol. Suas publicações: Educação, 1909; Oliveira Lima, 1914; O Brasil e a Educação Popular, 1917-1918; Revolução Pernambucana de 1817, 1917; Pela Educação Rural, 1919; São Paulo em 1920, 1920; A Constituição Brasileira e a Nossa Evolução Político-Constitucional, 1922; Os Deveres das Novas Gerações Brasileiras, 1923; Programas, 1925; Pela Confraternidade Americana, 1925; O Ensino na Capital do Brasil, 1926; Palavras de Fé, 1929; A organização da Educação em Pernambuco, 1929; O Problema do Método, 1932; Discursos e Conferências, 1933; As Linguas Vivas e Uma Experiência Brasileira, 1934; O Ensino das Linguas Vivas, 1935; Associação de Educação e Professores no Brasil, 1936; Tendências e Diretrizes da Escola Secundária, 1936; Introdução à Administração Escolar, 1939; A Sociedade Rural, seus Problemas e sua Educação, 1940; Fundamentos de Sociologia, 1940; A Educação nos Estados Unidos, 1940; Ideais e Preocupações de uma Época, 1941; Meus Heróis, 1942; Aspectos Brasileiros de Educação, 1942; Planejar e Agir, 1942; Estudos, 1943; A Educação para o Após-Guerra, 1944; Pensamento e Ação, 1945; A Educação para um Mundo Democrático, 1945; O Sentido da Evolução Cultural do Brasil, 1946; Discursos na Academia Brasileira de Letras, 1946; A Área Cultural e a Tendência para o Internacionalismo, 1949; As Faculdades de Filosofia e a Cultura Brasileira, 1949; Adolescência, seus Problemas e sua Educação, 1950; Visão Panorâmica dos Estados Unidos, 1951; A Ação Psico-Social na Organização do Estado, 1952; Nabuco e Junqueiro, 1953; Panorama Sociológico do Brasil, 1958; Vitor Hugo no Brasil, 1960; entre outros estudos que, em 1958, estavam sendo preparados para publicação.

Esteve, ainda, entre os imortais da Academia Brasileira de Letras, tendo ingressado em 30 de novembro de 1944, eleito para a cadeira número 14, sucedendo a Clóvis Beviláqua e sucedido por Fernando de Azevedo, quando veio a falecer em 30 de outubro de 1966.

De acordo com Niskier (2001), em sessão de saudade dedicada ao acadêmico Antônio Carneiro Leão, Austregésilo de Athayde pronunciou um discurso de Adeus e se referiu a ele nessas palavras:

Antônio Carneiro Leão foi talvez, dos brasileiros do nosso tempo, aquele que viu os seus livros, as suas obras, traduzidas em inglês e isso teria determinado que chamasse a atenção não só do Brasil; mas, sobretudo, ele passou a ser conhecido nos meios universitários norte-americanos e agora, traduzido em francês, tem também certo prestígio nos meios universitários franceses. Com os cargos que exerceu, teve oportunidade de trazer para o Brasil muitos mestres, e nesse intercâmbio foi realmente exemplar; procurava que viessem visitar-nos os maiores nomes das universidades francesas, americanas e argentinas. Poucos brasileiros terão feito tanto para promover o entendimento internacional que se processa, sobretudo no campo universitário. A verdade é que ele tinha um grande nome na $\mathrm{Ar}-$ gentina, nos meios culturais franceses e norte-americanos. É, assim, compreensível que, com o falecimento de Dewey, tendo então o presidente do Instituto de França pensado em dar-lhe um substituto na área da América, o nome de Carneiro Leão se impusesse a esta escolha. Ele, aliás, tinha desse fato um envaidecimento muito natural e compreensível, porque é uma honra extraordinária que alguém, 
num instituto como aquele, veja o seu nome colocado no mesmo nível de John Dewey. É, portanto, uma honra para a Academia Brasileira de Letras que ela tenha tido como um dos seus membros um homem que recebeu no mundo intelectual essa exaltação de ser, no Instituto de França, o substituto de John Dewey. (NISKIER, 2001, p. 18-19).

Cremos que as palavras de Niskier, expostas na citação anterior, são suficientes para demonstrar o quão relevante foram as ações e o pensamento de Carneiro Leão para a sociedade brasileira, em especial no que se refere ao âmbito educacional. De posse de alguns aspectos da biografia deste intelectual, apresentamos, de forma breve, alguns dados da pesquisa que instigou um aprofundamento de estudos acerca dos aspectos da Sociologia Educacional sob a perspectiva do mesmo.

\section{A Sociologia Educacional na Perspectiva de Carneiro Leão}

Tem se constituído tradição apresentar a introdução da Sociologia nos currículos oficiais por meio de Émile Durkheim e sua entrada na Universidade de Bordeaux, em 1887, na França. Este intelectual, aos 28 anos, assumiu a cátedra da disciplina, que foi reconhecida como verdadeira ciência, implantando-a nos cursos de Pedagogia.

Evidencia-se a Sociologia como uma ciência de percurso histórico peculiar, porque sua existência é intrínseca à necessidade de reorganização da sociedade de um determinado período. Sua trajetória, discutida em diferentes estudos, ${ }^{1}$ responde às demandas de compreensão e explicação social, uma busca intensa por mapear a realidade de uma sociedade e, a partir disso, buscar meios de intervir na mesma.

A preocupação em observar a vida em sociedade é anterior à consolidação da Sociologia como ciência, mas permanecer na observação ou descrição não respondia mais aos anseios de uma sociedade que passava por tantas transformações: "Os velhos paradigmas da ordem social, onde os lugares de cada um nas esferas de participação social, estavam a priori definidos, não mais davam conta da tarefa" (SILVA, 2007, p. 430).

Esclarece este autor que as mudanças que a sociedade vinha enfrentando se colocavam como desafios a serem superados pelos seus gestores, visto que a máquina do progresso em direção a uma nova ordem social estava acionada, a movimentação era constante e intensa. Camponeses tinham seu trabalho tomado pelas máquinas e, em busca de outras formas de sobrevivência, dirigiam-se para os centros urbanos, os quais se encontravam despreparados para atender a um contigente cada vez maior de população.

Nesse contexto, a Sociologia surgiu como um pensamento científico que objetivava não apenas conhecer a situação dos fatos sociais ocorridos até então, como buscar o entendimento e o conhecimento capazes de sanar os problemas gerados pela industrialização: "Uma sociedade de base agrária e comercial perturbava-se com o desenvolvimento da civilização industrial que começava a imperar. $O$ fato levaria as grandes inteligências ao estudo dos fenômenos sociológicos" (LEÃO, 1958, p. 48). 
É nesse momento histórico que, destaca Carneiro Leão (1958), iniciouse um movimento de estudos no sentido de compreender a situação da sociedade vigente, entender as dificuldades e problemas enfrentados pela população, conhecer a verdadeira realidade dessa nova sociedade, fundamentada na exploração do trabalho e no capital. Acrescenta o autor que a Sociologia tem suas origens em bases filosóficas, entretanto, a generalização é objetiva, já que advém da necessidade de conhecer e interpretar os fatos sociais ameaçadores ou complexos.

Carneiro Leão foi um intelectual inteiramente envolvido com questões sociais e políticas brasileiras, das quais a educação popular ocupou lugar de destaque. Sua formação em Ciências Jurídicas e Sociais possibilitou-lhe aprofundar seus estudos com relação à educação e encontrou na Sociologia uma alternativa para tentar corrigir ou transformar a realidade social, uma vez que entendia que somente um magistério apropriado, conhecedor da nossa realidade, poderia proporcionar a educação adequada ao interior do país.

No Brasil, pode-se considerar Rui Barbosa ${ }^{2}$ como o primeiro intelectual a sinalizar para a necessidade da Sociologia em seus aspectos educacionais quando propôs em um de seus pareceres, ${ }^{3}$ em 1870 , a substituição da disciplina de Direito Natural pela de Sociologia, alegando que o Direito tinha mais afinidade com as relações sociais do que com um pretenso "estado da natureza".

No entendimento de Carneiro Leão, esta ciência, como disciplina, seria capaz de mapear a situação real em que se encontrava a sociedade brasileira e, assim, modernizá-la. ${ }^{4}$ Entretanto, fazer-se-ia necessário avaliar exatamente do que se tratava essa Sociologia, uma vez que a doutrinação não era o objetivo de sua utilização, mas apenas o que fosse indispensável à melhor compreensão de sua função científica.

Se se tratar de uma sociologia doutrinária, um estudo das razões, significação, definição dessa matéria, ou de uma espécie de filosofia da história, iremos apenas arranjar mais um motivo para torneios verbais. A sociologia imprescindível a uma Escola Normal é a que trate dos problemas sociais, sobretudo contemporâneos. É uma experimentação social. (LEÃO, 1929, p. 18).

Com a preocupação em formar professores que fossem capacitados para a aplicação do método sociológico, Leão procurou organizar algumas questões que julgava serem importantes e elaborou um conjunto de lições, cujo título dado foi Fundamentos de Sociologia. Era preciso levar aos futuros professores a maneira correta de tratar a Sociologia e de levá-la ao ensino escolar.

O ensino da referida disciplina, nessa perspectiva, deveria ser iniciado a partir da formação do docente, a qual se dava no âmbito das Escolas Normais. Num momento em que o debate sobre o processo de modernização do país fervilhava, início do século XX, seu ministério era importante para que, por meio das ações realizadas no interior da escola, a sociedade pudesse ter um novo reflexo. Nesse sentido, Leão demonstrou sua preocupação com a educação à medida que apontava a disciplina de Sociologia como a mais adequada para se alcançar uma organização esperada para o Estado brasileiro. 
No período tratado, por volta de 1928, Leão encontrava-se elaborando a reforma educacional no Estado do Pernambuco, a pedido do então governador Dr. Estácio Coimbra. Eis algumas das providências consideradas relevantes para a organização da Educação no Estado de Pernambuco no que concerne, em especial, às Escolas Normais:

[...] a divisão do curso existente em dois períodos é tudo quanto há de mais exeqüível. $\mathrm{O}$ estágio continua o mesmo. Nos três primeiros anos ministra-se a cultura geral, nos dois últimos o profissional. Depois de três anos de estudo de línguas, artes e ciências, o aluno frequentará dois anos, em contato quase exclusivo com as matérias formadoras do mestre, um verdadeiro instituto de pesquisas pedagógicas. (LEÃO, 1929, p. 15).

Esta seria, então, a organização estrutural do Curso Normal, havendo ainda a preocupação com a vocação do professor a ser formado e a maneira de selecionar os mesmos:

Aí pode-se, desde que funcione o "Instituto de Seleção e Orientação", fechar as portas aos candidatos, cujas aptidões forem evidentemente negativas para a missão de educador, embora hajam sido aprovados em todas as matérias do curso geral. Em compensação, poderá matricular-se um certo número de pessoas que, sem terem vindo do curso geral, queiram e possam, conforme exame vestibular e de aptidão, obter diploma de professor. Portadores de diplomas de curso secundário, pessoas de cultura, professores por escolas normais de outros Estados, poderão, deste modo, tornar-se excelentes mestres em Pernambuco. Bastará que o governo, todos os anos ofereça algumas matriculas no curso profissional a candidatos de fora da Escola. (LEÃO, 1929, p. 15-16).

Os profissionais que assumiriam o magistério, após a realização dos Cursos Normais, precisavam estar aptos para a ação docente, por isto, a capacitação dos mesmos deveria basear-se em uma organização de disciplinas diferenciada. Dessa forma, Leão propôs uma nova distribuição das disciplinas, destacando a disposição de algumas:

Educação moral e cívica, por exemplo, parte integrante da cadeira de pedagogia, deixa essa disciplina em paz. A educação cívica passa a ser ministrada com História do Brasil, o que parece mais lógico. Educação moral não será mais feita em preleções, e sim em todas as matérias, nos momentos oportunos. Sempre me pareceu que, na cadeira de higiene, se pudesse dar uma compreensão mais viva do valor da sobriedade, dos males da intemperança, do que em considerações abstratas, em discursos ou dissertações mais ou menos convencionais e solenes. Além disso, serão criadas quatro cadeiras novas, duas no curso geral - inglês e anatomia e fisiologia humanas - e duas no curso profissional - didática e sociologia. (LEÃO, 1929, p.16).

Nota-se que ele considerava imprescindível criar algumas cadeiras, entre elas a de Sociologia, já que o Brasil não conhecia a si próprio. Era necessária uma 
cadeira que possibilitasse conhecer, de modo profundo, a realidade brasileira, que estudasse, de forma precisa e científica, a vida social, regional e nacional que se fazia presente na nossa sociedade (LEÃO, 1963).

A disciplina de Sociologia, em seus aspectos educacionais, era muito valorizada pelo autor. Tal afirmativa pode ser confirmada por meio das palavras que ele utiliza na introdução sobre a reforma de Pernambuco: "Para ministrar essa matéria com tal orientação, só conhecemos no Estado, Gilberto Freyre, cuja cultura sociológica se fez no convívio dos melhores mestres" (LEÃO, 1963, p. 14). Dessa forma, em acordo com Estácio Coimbra, governador do Estado, criou-se a cadeira de Sociologia, que foi provida imediatamente pelo professor Gilberto Freyre.

Na concepção de Leão (1963), a objetividade científica da Sociologia era extremamente relevante, uma vez que uma filosofia social ou filosofia da história não serviria aos objetivos da época. $\mathrm{O}$ autor considerava que era preciso estudar e conhecer uma sociedade para educá-la com segurança científica no sentido de sua própria civilização.

Nesta perspectiva, entende-se que a ordem do dia era modernizar, ou seja, organizar uma nova sociedade urbana e industrial que, a partir das contribuições que o desenvolvimento das ciências traria, seria possível preparar o homem para viver, trabalhar e interagir com essa nova sociedade (TEIXEIRA, 2000).

Uma formação docente de qualidade, portanto, era essencial para a sociedade que se apresentava. Leão considerava esse aspecto de grande importância para a formação da nacionalidade brasileira (NISKIER, 2004). Como estava atento aos movimentos sociológicos externos ao país, observou que "nos Estados Unidos os movimentos sociológicos mais recentes realizam-se nas escolas de professores" (LEÃO, 1963, p. 13). Considerava serem essas escolas as responsáveis em dar condições aos futuros professores de vivenciarem experiências da realidade social, as quais os tornariam capazes de observar e conhecer o suficiente para que educassem para a sociedade e para a vida.

O autor primava pelos trabalhos de campo sociológico e, tendo em vista que os programas escolares brasileiros, "que se copiavam reciprocamente [...]" (LEÃO, 1963, p. 13), eram inspirados sempre em programas estrangeiros, considerava o currículo escolar do país vazio de ação construtiva, por nada lhe ser acrescentado em termos de conteúdo. Para o autor,

A sociologia, estudo das origens, da estrutura, das mudanças, do desenvolvimento nas relações sociais, tem de manter-se em contato íntimo com a sociedade em que é ministrada ou falta-lhe nexo num currículo escolar. Outro não é o motivo porque uma escola sociológica, e das mais ilustres dos Estados Unidos - a Escola de Chicago - vê, no estudo das relações entre o homem, a terra, a planta, os animais e os outros homens, da mesma região, a finalidade primeira das ciências sociais. (LEÃO, 1963, p. 14). 
Tendo em vista a importância da modernização nacional, aliada à relevância do papel da Sociologia num currículo escolar, é notória a justificativa da importância dada ao professor e à sua formação em bases sociológicas. A Sociologia Educacional proporcionaria ao futuro professor conhecer a realidade educacional brasileira e daria condições de pensar sua ação sobre a mesma. Nada poderia ser mais coerente que tratar da formação daqueles que iriam formar ou educar as futuras gerações brasileiras. Realizar essa formação mediante o estudo aprofundado do berço dessas gerações, conhecendo sua realidade social, suas verdadeiras vivências, problemas e raízes era primordial.

Para Leão (1963), a Sociologia seria a disciplina capaz de impulsionar as condições educacionais necessárias para a educação que o país precisava: "Examinando a ação física, mental, moral e social, observando o equipamento material e os fatores imateriais do grupo, pode-se chegar, com precisão relativa, ao conhecimento objetivo da vida em determinada sociedade" (LEÃO, 1963, p. 14).

É importante ressaltarmos que a Sociologia, como citado anteriormente, foi pensada num momento de constantes transformações da sociedade nos âmbitos econômico, social e cultural, dentre outros. A relação que se estabeleceu entre essa ciência e, por sua relevância, mais tarde, disciplina, e a Educação, num aspecto mais amplo e complexo, há muito é discutida. Desde as iniciativas institucionais de Anísio Teixeira, no cenário brasileiro, as quais buscavam analisar a problemática educacional com base nos conceitos alavancados pelas ciências sociais, a Sociologia da Educação tem recebido maior destaque como objeto de estudo.

Dentre as diversas ramificações de estudos da Sociologia, destacamos a Sociologia da Educação e enfatizamos esta como uma especificidade da primeira, a qual tem como pressuposto um estudo mais aprofundado no que se refere aos processos sociais do ensino e da aprendizagem. Assim, entende-se que a referida disciplina analisa os processos nos quais a sociedade está fundamentada para o seu desenvolvimento.

Investigar a aproximação entre Sociologia e Educação é um aspecto importante para que se possa compreender a Sociologia da Educação como especificidade da Sociologia. Entretanto, tendo em vista os objetivos deste texto, ater-nos-emos em sinalizar a relevância dessa discussão para que se tenha clarificada a questão das relações sociais e educacionais. Em uma futura publição, objetivamos observar, de forma mais profunda, a Educação como especificidade da Sociologia a partir do momento em que é reconhecida como tal e, com isso, justificar o debate acerca da disciplina de Sociologia no referido estudo. Esperamos, em breve, publicar os resultados desta investigação.

\section{Considerações finais}

Conforme explícito no início deste trabalho, objetivamos apresentar algumas considerações acerca da Sociologia Educacional na perspectiva de Antônio Carneiro Leão (1887-1966). Para tanto, buscamos revelar, brevemente, os seus dados biográficos, haja vista sua importante atuação política e educacional no cenário brasileiro, bem como elencar algumas considerações sobre o autor da Sociologia Educacional e sua relevância para a formação de professores. 
Sabemos que o referido autor atuou na campanha pela educação popular, defendendo a necessidade de sua organização no Brasil (SILVA, 2006). Na luta pela educação desejada, participou de inúmeras conferências e palestras, elaborando diversos artigos e dedicando seus esforços a obras voltadas para a educação e, especialmente, o estudo da sociedade brasileira por meio da Sociologia, uma vez que considerava de extrema importância uma sociedade estudar a si própria para se conhecer. Para o autor, nenhuma disciplina seria "[...] mais adequada à orientação de tais objetivos do que a sociologia." (LEÃO, 1963, p. 13).

Evidenciamos que a própria biografia e currículo do autor em estudo são suficientes para demonstrar a imensa contribuição que deu para a sociedade brasileira, em especial no âmbito educacional. Sua participação nos processos político, educacional e cultural do país foi peculiar.

Há muito a Sociologia da Educação tem conquistado seu espaço no meio acadêmico. Sua relevância para a formação de professores pode ser analisada a partir da disposição em que se encontra na estrutura curricular das licenciaturas de universidades conceituadas do país. Embora esta discussão se apresentasse desde o século $\mathrm{XIX}$, como vimos anteriormente, só tomou maior consistência no século XX, quando intelectuais renomados se propuseram a discutir sua importância, tais como: Carneiro Leão, Fernando de Azevedo, Gilberto Freyre, entre outros.

$\mathrm{Na}$ concepção de Carneiro Leão, grosso modo, a Sociologia seria como uma arma, um ponto de partida para mapear a realidade social do país e, a partir de então, agir na educação de forma a atingir os objetivos do período. Para o autor, "a sociologia útil, em uma escola normal, era a que estudasse os problemas sociais contemporâneos pelo método da experimentação. [...] Só à luz da sociedade em que vivemos podemos organizar a educação do povo"(LEÃO, 1963, p. 13).

Contudo, podemos dizer que a disciplina de Sociologia Educacional ou Sociologia da Educação, conforme nomenclatura atual, analisa tanto os processos institucionais e organizacionais, nos quais a sociedade se fundamenta para o provimento da educação, como as relações sociais que são estabelecidas no desenrolar desse processo. Avaliamos que é na formação docente, segundo Carneiro Leão, que se encontra o centro dessa questão. Nesta direção, evidenciamos, como fundamentalmente coerente, a abordagem dos estudos sociológico-educacionais nos cursos de formação de professores, sejam em nível técnico ou superior.

\section{Referências}

BOTTOMORE, T. B. Introdução à sociologia. 5. ed. Rio de Janeiro: Zahar; Brasília: INL, 1973 (Biblioteca de Ciências Sociais).

COHN, G. Crítica e resignação: fundamentos da sociologia de Max Weber. 1j. ed. São Paulo: T. A. Queiroz, 1979.

LEÃO, A. C. Organização da educação no Estado de Pernambuco. Ato n. 1239 Exmo. Sr. Dr. Governador do Estado, de 27 de dezembro de 1928. Recife: Imp. Official, 1929.

. Panorama sociológico do Brasil. Rio de Janeiro, DF: Centro Brasileiro de Pesquisas Educacionais - INEP, 1958. 
LEÃO, A. C. Fundamentos de sociologia. São Paulo: Melhoramentos, 1963.

NISKIER, A. O educador Carneiro Leão. Discurso de posse no Instituto Histórico e Geográfico de São Paulo, em 31 de outubro de 2001. p. 14-19. Disponível em: <http://www.academia. org.br/abl/media/prosa7a.pdf>. Acesso em: 05 out. 2009.

. As idéias da escola nova. In: CM News, segunda-feira, 08 mar. 2004. Disponível em: <http://news.cmconsultoria.com?index.php>. Acesso em: 10 set. 2009.

MACHADO, M. C. G. O projeto de Rui Barbosa: O papel da educação na modernização da sociedade. REUNIÃO ANUAL DA ANPED, 23. Educação não é privilégio (Centenário de Anísio Teixeira). Caxambu/MG, 24 a 28 set. 2000. Disponível em: <http://www.anped.org.br/ reunioes/23/textos/0208t.PDF> Acesso em: 05 out. 2009.

. Rui Barbosa. (Verbete). In: LOMBARDI, J. C.; SAVIANI, D.; NASCIMENTO, M. I. M. (Orgs.). Navegando pela história da educação brasileira. Campinas, SP: FE; HISTEDBR, 2006. DR-Rom.

MARTINS, C. B. O que é sociologia? 38 ed. São Paulo: Brasiliense, 1994.

PACHECO FILHO, C. Diálogo de surdos: as dificuldades para a construção da sociologia e de seu ensino no Brasil. 6 volumes. 1085 f. Dissertação (Mestrado em Educação). Faculdade de Educação da USP, São Paulo, 1994.

SILVA, J. A. P. Carneiro Leão e a proposta de organização da educação popular brasileira no início do século XX. 131 f. Dissertação (Mestrado em Educação) - Universidade Estadual de Maringá. Maringá, PR, 2006.

SILVA, T. E. M. Trajetórias da sociologia brasileira: considerações históricas. Cronos, Natal, v. 8, n. 2, p. 429-449, jul./dez. 2007. Disponível em: <http://www.cchla.ufrn.br/cronos/pdf/8.2/ d4.pdf>. Acesso em: 22 out. 2009.

TEIXEIRA, A. Pequena introdução à filosofia da educação: Escola progressiva ou a transformação da escola. 6. ed. Rio de Janeiro: DP\&A, 2000.

TESKE, O. (Coord). Sociologia: textos e contextos. Canoas: ULBRA, 1999.

\section{Notas}

\footnotetext{
${ }^{1}$ Destacam-se autores como Bottomore (1973), Cohn (1979), Martins (1994), Teske (1999), entre outros, que discutem com propriedade tal temática.

${ }^{2}$ Segundo Machado (2006), pesquisadora desse grande expoente da educação brasileira, Rui Barbosa foi um parlamentar e participou de forma ativa na vida política brasileira por mais de cinquenta anos. Foi relator da Comissão de Instrução Pública, cuja obrigação era apreciar o Decreto n. 7.247, de 19 de abril de 1879, de autoria do ministro Carlos Leôncio de Carvalho. Este Decreto reformava o ensino primário e secundário no município da Corte e o ensino superior em todo o Império. O conjunto de relatos escritos por Rui Barbosa ficou conhecido como Pareceres.

${ }^{3}$ Consideramos importante destacar essa sinalização, por se tratar de uma perspectiva interessante, mesmo que seu Parecer não tenha sequer sido votado. Na ocasião, Rui Barbosa considerava o ensino de Sociologia mais viável, uma vez que o Direito Natural, para ele, era excessivamente metafísico e recomendou que houvesse a inclusão das disciplinas: Elementos de Sociologia e de Direito Constitucional no curso ginasial; Instrução Moral e Cívica, abrangendo as Noções Fundamentais de Direito Pátrio e Economia Política, nas Escolas Normais e Sociologia nas Faculdades de Direito (PACHECO FILHO, 1994).

${ }^{4}$ De acordo com Machado, em seu estudo acerca de O Projeto de Rui Barbosa: o papel da educação na modernização da sociedade, de 2000, o autor entendia que, para a modernização da sociedade brasileira,
} 
fazia-se necessário um rompimento interno das barreiras que impediam que o país participasse do movimento mais geral do período em questão. Era preciso vencer a ignorância do analfabetismo - educação -, considerada por muitos intelectuais como mola propulsora do desenvolvimento econômico, industrial e cultural brasileiro, por meio do ensino da ciência.

* Doutoranda da Universidade Estadual de Maringá, Maringá, Paraná, Brasil.

** Professora Doutora da Universidade Estadual de Maringá, Maringá, Paraná, Brasil.

\section{Correspondência}

Rosilene de Lima - Colégio Estadual Itacelina Bittencourt. Rua Timbiras, 156, Cianortinho. CEP: 87200000 - Cianorte, Paraná, Brasil.

E-mail:1ene.lim@hotmail.com-mcgmachado@uem.br

Recebido em 05 de maio de 2014

Aprovado em 28 de agosto de 2014 